\title{
PROPOSTAS PARA IR ALÉM DA “PERSISTÊNCIA DA BURRICE” E OUTRAS “IDEIAS ZUMBI" NA EJA
}

\author{
Sandra Regina Sales
}

Gustavo E. Fischman ${ }^{(*)}$

Você já se perguntou alguma vez o que faz ideias impensáveis se tornarem pensáveis? Ou talvez, de uma forma menos ambiciosa: o que é necessário para mudar o modo de as pessoas pensarem e sentirem em relação a tradições que causam danos? Acreditamos que explorar a maneira de abordar estas questões não é um exercício trivial para cientistas sociais, e é particularmente relevante para pesquisadores em educação de jovens e adultos (EJA), bem como para os que atuam na formação de professores.

A EJA no Brasil parece ser caracterizada em documentos oficiais (BRASIL, 2008); por pesquisadores do campo (RUMMERT, VENTURA, 2007; GALVÃO, DI PIERRO, 2007); pela mídia (FISCHMAN, SALES, 2012) como um sistema historicamente impactado por circunstâncias adversas que afetam negativamente a alunos e educadores e, sobretudo, aos mais vulneráveis.

Uma das evidências dessa caracterização negativa, muito corrente na sociedade brasileira, inclusive entre os próprios alunos da EJA, é a ideia de que aqueles que não aprendem na infância são considerados (ou se consideram) "burros" ou "cabeças-duras", que terão muita dificuldade para aprender fora da dita idade certa, ou não aprenderão já que "papagaio velho não aprende a falar". $\mathrm{Na}$ falta de um melhor nome, chamamos esta ideia de "persistência da burrice" e caracterizamos a mesma como uma ideia "zumbi."

O economista vencedor do Prêmio Nobel Paul Krugman (2014, p. 3) rotulou de "ideias zumbis" aquelas que "deveriam ter sido mortas pela evidências, mas se recusam a morrer". Uma crença zumbi é frequentemente fortalecida por meio de rápidos processos automáticos de

\footnotetext{
${ }^{(*)}$ Sandra R. Sales. Doutora em Educação pelo Programa de Pós-Graduação em Educação da UERJ. Atua como docente do Departamento de Educação e Sociedade do Instituto Multidisciplinar e do Programa de Pós-Graduação em Educação, Contextos Contemporâneos e Demandas Populares da UFRRJ. Desenvolve pesquisas sobre Educação de Jovens e Adultos, Mídia e Educação e Políticas de Ação Afirmativa no Ensino Superior. Currículo: <http:// buscatextual.cnpq.br/buscatextual/visualizacv.do?id=K4763726D8>.

Gustavo E. Fischman. Doutor em Ciências Sociais e Educação Comparada pela University of California, Los Angeles. Atua como docente do Departamento de Educação Mary Lou Fulton da Arizona State University e está vinculado ao Programa de Pós-Graduação em Políticas Educativas desta universidade. Desenvolve pesquisas no campo das políticas educativas e mobilização do conhecimento. Currículo: <http://buscatextual.cnpq.br/buscatextual/visualizacv.do? id $=\mathrm{K} 4428424 \mathrm{~A} 0>$.
} 
pensamento corretamente errados (para uma discussão mais detalhada da relevância dos processos “corretamente errados", ver HAAS, FISCHMAN, BREWER, 2015). Estes processos corretamente errados são "rápidos" no sentido de que não fazem parte de processos de reflexão mais lentos e geram ideias que parecem "certas" mesmo na presença de evidências fortemente contrárias. Nestes casos, é comum recorrer ao nosso preconceito confirmatório e justificar nossas conclusões com um conjunto post hoc lógico de argumentos para sustentar o que o nosso instinto já nos disse deva estar certo (HAIDT, 2012). O pensamento corretamente errado é uma influência comum e poderosa para se formular discussões sobre tópicos e questões, especialmente aqueles que tocam nossas emoções. Em questões educacionais, eles são muitos e difíceis de serem mudados.

Destacamos que as consequências da noção da "persistência da burrice" são extremamente danosas para a EJA, como mostraremos a seguir, ao discutir tensões relacionadas ao financiamento e à persistência da noção de suplência na definição de políticas de EJA. ${ }^{1}$

A primeira consequência visível é fundamentalmente a justificativa de decisões de não investir recursos públicos no campo da EJA. Na história recente da EJA, a recusa em garantir financiamento público para os sujeitos que "se desviaram da norma" (SALES, PAIVA, 2014) foi a tônica em vários momentos. Nessa perspectiva, o investimento deveria ser feito nas crianças, pois o problema do analfabetismo e da baixa escolaridade seriam resolvidos com o tempo.

Um exemplo muito lembrado no campo, nesse sentido, é o discurso de um ministro da educação que à imprensa declarou:

$\mathrm{O}$ adulto analfabeto já encontrou seu lugar na sociedade. Pode não ser um bom lugar, mas é o seu lugar. Vai ser pedreiro, vigia de prédio, lixeiro ou seguir outras profissões que não exigem alfabetização. Alfabetizar o adulto não vai mudar muito a sua posição dentro da sociedade e pode até perturbar. Vamos concentrar os nossos recursos em alfabetizar a população jovem. Fazemos isso agora, em dez anos desaparece o analfabetismo. (Jornal do Comercio, Rio de Janeiro, 12/10/1991 apud GALVÃO, DI PIERRO, 2007, p. 60).

Outra consequência relacionada com a noção zumbi sobre a "persistência da burrice" foi a Emenda Constitucional n. 14/96 por meio da qual o Governo Federal suspendeu o compromisso que constava nas Disposições Transitórias da Constituição Federal de 1988 de erradicar o analfabetismo em 10 anos (HADDAD, 1998). Ao se desresponsabilizar de importante compromisso, o governo

\footnotetext{
${ }^{1}$ Sobre essa questão, Oliveira (1999, p. 60-61) destaca que "peculiaridades da etapa de vida em que se encontra o adulto fazem com que ele traga consigo diferentes habilidades e dificuldades (em comparação com a criança) e, provavelmente, maior capacidade de reflexão sobre o conhecimento e sobre seus próprios processos de aprendizagem". Di Pierro (2005, p. 1119), por sua vez, faz referência a um processo que denomina "transição de paradigmas" que tem início em 1997 quando a V Conferência Internacional de Educação de Jovens e Adultos (V CONFINTEA) proclamou o "direito de todos à educação ao longo da vida".
} 
central abre mão de seu papel de induzir e de suplementar políticas públicas de alfabetização e também de aumento de escolaridade frente aos demais entes federados.

Outra política de financiamento diz respeito ao Fundo Nacional de Manutenção e Desenvolvimento do Ensino Fundamental e Valorização do Magistério (FUNDEF, Lei 9.424/96) e ao veto da Presidência da República ao uso dos recursos do Fundo com a EJA, ou seja, estados e municípios foram impedidos de contabilizar as matrículas de EJA para o repasse de recursos do referido Fundo. O Fundef foi substituído pelo Fundo Nacional de Manutenção e Desenvolvimento da Educação Básica e Valorização dos Profissionais da Educação (Fundeb), em 2006, por meio da Lei 11.494/07. Na nova Lei foram definidos novos critérios para distribuição dos recursos, permitindo-se a inclusão das matrículas de EJA, educação infantil e ensino médio (FÁVERO, 2011). Entretanto, Machado (2011) identifica um processo de "discriminação" dos alunos da EJA, pois o valor aluno/ano dessa modalidade é inferior aos demais alunos. Machado (2011, p. 101-102) indica os mecanismos gerados da discriminação:

[...] enquanto o valor referência para a definição do custo aluno é 1, para os alunos matriculados nos primeiros anos do ensino fundamental urbano, o valor do aluno da EJA equivale a $80 \%$ desse valor referência. Outro limite que a EJA possui é a criação de uma trava no gasto dos recursos do FUNDEB, que representa dizer que os gastos com as matrículas da EJA só poderão atingir o limite de $15 \%$ do que for recebido do fundo.

A segunda consequência associada à noção zumbi da "persistência da burrice" é a continuidade de políticas fundadas na concepção da suplência. Vigente desde a ditadura militar, a Doutrina do Ensino Supletivo, que se inspira em uma concepção compensatória de educação, continua viva no Brasil. Entendido como um "instrumento de reposição de estudos não realizados na infância ou adolescência" (DI PIERRO, 2005, p. 1118), o ensino supletivo, bem como a concepção compensatória, tendem a não enxergar os jovens e adultos em suas necessidades, interesses, histórias e saberes. Ao contrário, fixa-se na transmissão, via de regra, infantilizada, de conteúdos que estes deveriam ter aprendido na infância.

Vale destacar que até a legislação brasileira, mesmo ao garantir o direito à educação aos jovens e adultos, se refere a estes como aqueles que não frequentaram a escola na idade própria ou na idade regular. É o caso da Constituição Federal que em seu Art. 208, inciso I, que é crucial para a garantia do direito aos sujeitos da EJA, afirma a "educação básica obrigatória e gratuita dos quatro aos dezessete anos de idade, assegurada inclusive sua oferta gratuita para todos os que a ela não tiveram acesso na idade própria”. (Grifo nosso.) 
Similarmente, a Lei de Diretrizes e Bases da Educação Nacional (LDBEN, Lei 9.394/96), ao mesmo tempo em que assegura avanços indiscutíveis para a EJA como o respeito à diversidade e às especificidades dos alunos, mantém as expressões idade própria e agrega outra com o mesmo sentido: idade regular:

Art. 37. A educação de jovens e adultos será destinada àqueles que não tiveram acesso ou continuidade de estudos no ensino fundamental e médio na idade própria.

$\S 1^{\circ}$. Os sistemas de ensino assegurarão gratuitamente aos jovens e aos adultos, que não puderam efetuar os estudos na idade regular, oportunidades educacionais apropriadas, consideradas as características do alunado, seus interesses, condições de vida e de trabalho, mediante cursos e exames. (Grifos nossos.)

A LDBEN vigente vai além na manutenção do que vimos denominando ideias zumbi ao retomar explicitamente no Art. 38 a expressão cursos e exames supletivos: "Os sistemas de ensino manterão cursos e exames supletivos, que compreenderão a base nacional comum do currículo, habilitando ao prosseguimento de estudos em caráter regular”. (Grifos nossos.)

Os exemplos anteriores sustentam a nossa perspectiva de que a situação do campo da EJA exige um movimento de nossa parte para além da denúncia dos problemas e em direção à proposição de alternativas. Dentro da grande quantidade de problemas identificados, a formação de professores para atuar no campo da EJA parece estar ganhando um lugar central, em particular a busca de alternativas para abordar o problema de se formar professores de EJA que atentem para as especificidades e a diversidade do sujeitos da EJA. ${ }^{2}$

Nesse trabalho, apresentamos os resultados de uma pesquisa realizada em 2014 e 2015 sobre os Cursos de Pedagogia oferecidos em Instituições de Ensino Superior (IES) do estado do Rio de Janeiro, a partir de uma revisão das grades curriculares dos cursos e de entrevistas em profundidade com professores que ministravam disciplinas de EJA em IES públicas e privadas sediadas no mesmo estado. ${ }^{3}$

\footnotetext{
${ }^{2}$ Essa é uma temática que tem merecido atenção especial dos professores e pesquisadores do campo da EJA, e que se manifesta na realização de cinco edições do "Seminário Nacional de Formação de Educadores de Jovens e Adultos" ocorridos em 2006, 2008, 2010, 2012 e 2015.

${ }^{3}$ A referida pesquisa é parte de um projeto maior denominado "Que educação para que cidadão? Discursos influentes na Educação de Jovens e Adultos no Brasil (1995-2015)", que contou com financiamento da CAPES e conta atualmente com o apoio da Faperj e do CNPq. Participam da pesquisa Brienne Aparecida Cardoso de Souza (Bolsista FAPERJ), Carolina Sthefany Almeida da Silva (bolsista Faperj), Júlia Alves da Silva (Bolsista Pibic), Manoela Tavares Carvalho da Silva (ex-bolsista Faperj e voluntária), Márcia da Cruz Silva Vieira (voluntária) a quem agradecemos pela assistência e pelo apoio.
} 


\section{AS ETAPAS DA PESQUISA: PRIMEIROS ACHADOS}

O primeiro desafio da pesquisa foi identificar as IES que oferecem cursos de Pedagogia no estado do Rio de Janeiro. Após refletir e experimentar algumas possibilidades, optamos por fazer a busca no E-MEC, sistema de tramitação eletrônica dos processos de Credenciamento e Recredenciamento de IES, Autorização, Reconhecimento e Renovação de Reconhecimento de Cursos. ${ }^{4}$

Segundo levantamento realizado no $E-M E C$ em 2014, havia 93 cursos de Pedagogia no estado do Rio de Janeiro na modalidade presencial em 49 IES, já que como parte de suas políticas de expansão é comum no Brasil que as IES possuam além da sede, unidades que podem ser na mesma cidade ou em cidades diferentes. ${ }^{5}$

Além disso, a pesquisa revelou que o curso de Pedagogia na modalidade presencial estava presente em 29 dos 92 municípios do estado. Isso significa que não há cursos de Pedagogia na modalidade presencial em 63 municípios, ou seja, em cerca de dois terços dos municípios os professores continuam sendo formados em Cursos de Formação de Professores de nível médio ou em cursos de pedagogia a distância.

Quando observamos essa distribuição pelas oito Regiões político-administrativas do estado do Rio de Janeiro, constatamos a alta concentração de cursos na Região Metropolitana que reunia 63 dos 93 cursos, ou mais de dois terços, sendo que 35 - o que representa mais da metade encontravam-se na cidade do Rio de Janeiro. Os demais 30 cursos estavam distribuídos da seguinte forma: sete na Região Norte Fluminense, seis na Região Serrana, cinco nas Regiões Noroeste Fluminense e Região do Médio Paraíba, quatro na Região das Baixadas Litorâneas, dois na Região Centro-Sul Fluminense e um na Região da Costa Verde.

Identificadas as IES, partimos para a segunda etapa da pesquisa que foi buscar em seus sítios ou portais informações sobre o curso de Pedagogia. No primeiro momento, buscamos as grades curriculares para verificar se os cursos ofereciam pelo menos uma disciplina sobre EJA. Dos 93 cursos, não encontramos informações sobre 29, pois não disponibilizavam sítios ou grades curriculares.

Identificamos 63 que ofereciam disciplinas obrigatórias sobre EJA e um curso que oferecia apenas disciplinas eletivas. Dos 63 que ofereciam disciplinas obrigatórias, um oferecia sete, seis

\footnotetext{
${ }^{4}$ A pesquisa foi realizada no site <http://emec.mec.gov.br>.

${ }^{5}$ Cabe destacar que a Universidade Estácio de Sá sozinha oferecia 14 cursos em diferentes unidades de oito municípios, quando a pesquisa foi realizada.
} 
ofereciam três, 14 ofereciam duas e 42 ofereciam apenas uma disciplina respectivamente. Apenas três cursos de Pedagogia no estado de Rio de Janeiro não ofereciam disciplina sobre EJA.

Apesar de a maior parte dos cursos oferecerem apenas uma disciplina, merece destaque o fato de um terço deles oferecerem duas ou três. Um destaque especial fazemos ao curso que oferece sete disciplinas, o que configura um campo na formação do Pedagogo. ${ }^{6}$ Para nós, tal fato demonstra um certo reconhecimento da importância do campo da EJA no âmbito da formação docente, pois sabemos que negociações e acordos em torno de um projeto de curso e de uma matriz curricular dentro dos Colegiados de Cursos, de Faculdades, de Departamentos ou de Escolas de Educação não são fáceis.

A terceira etapa consistiu na realização de entrevistas com professores que ministravam disciplina/s sobre EJA. Para a constituição da amostra dos cursos consideramos basicamente a localização geográfica dos campi, segundo a Região político-administrativa do estado e a categoria administrativa das IES, ou seja, públicas ou privadas. Inicialmente pensamos em entrevistar nove professores, sendo dois da Região Metropolitana e um de cada uma das demais regiões. Tínhamos interesse em ampliar nosso conhecimento sobre a configuração da EJA fora das grandes universidades públicas da Região Metropolitana, cujos professores já são, de uma forma ou de outra, nossos conhecidos.

Buscamos fazer nosso primeiro contato por telefone com os coordenadores dos cursos, o que nem sempre foi possível, ou diretamente com os professores quando já possuíamos os contatos. Em alguns casos buscamos informações sobre os coordenadores com funcionários das IES que nos forneciam telefones ou e-mails. Aos coordenadores enviamos por e-mail uma carta na qual nos apresentávamos, informávamos os objetivos da pesquisa e solicitávamos contato com os professores de EJA. Nesse processo, não conseguimos contato com a coordenação dos dois únicos cursos que ofertavam EJA na Região das Baixadas Litorâneas e não conseguimos agendar a entrevista com a professora de EJA do único curso que oferecia EJA na Região Centro-Sul Fluminense.

\footnotetext{
${ }^{6} \mathrm{O}$ curso em questão é o da Universidade do Estado do Rio de Janeiro, Campus Maracanã. Segundo o professor entrevistado "o que acontece é que a EJA pra nós é um campo da formação do pedagogo. [...] um campo da formação com base na docência, ou seja, a formação do licenciado para anos iniciais do ensino fundamental para crianças, jovens e adultos e outro campo da Pedagogia fica sendo a Pedagogia nas instituições e nos movimentos sociais". As sete disciplinas às quais nos referimos compõem esse segundo campo de formação e são: 1) Abordagens Pedagógicas na Educação de Jovens e Adultos ; 2) Educação Continuada e Perspectivas em Redes de Conhecimento; 3) Educação de Jovens e Adultos; 4) Trabalho, Educação e Desenvolvimento Profissional; 5) Educação e Movimentos Sociais: aspectos históricos e políticos; 6) Educação para a Gestão de Projetos Socioambientais; 7) Pedagogia nas Instituições e nos Movimentos Sociais: Estágio Supervisionado.
} 
Assim, foram entrevistados sete professores: um da Universidade do Estado do Rio de Janeiro (UERJ); um da Faculdade de Belford Roxo (FABEL); um, o Instituto de Educação de Angra dos Reis (IEAR), campus da Universidade Federal Fluminense de; um da Universidade Federal Fluminense de Santo Antônio de Pádua (UFF-SAP); um da Universidade Católica de Petrópolis (UCP); um da Faculdade de Filosofia Ciências e Letras de Macaé (FAFIMA); e um do Centro Universitário Geraldo Di Biase (UGB).

As entrevistas foram feitas com professores da EJA que atuam em cursos de pedagogia no estado de Rio de Janeiro, usando um roteiro com dez questões nas quais foram exploradas perspectivas pessoais; como a EJA aparece na grade curricular dos cursos; a percepção do conjunto de professores do curso; a avaliação dos alunos sobre os cursos de EJA; a perspectiva sobre os desafios vivenciados nas redes de ensino; as principais influências recebidas; as temáticas que consideram relevantes; as perspectivas sobre homogeneidade e diversidade; e metáforas ou imagens representativas.

$\mathrm{Na}$ análise dos resultados das três etapas, a relação entre teoria e prática pedagógica na EJA foi a tensão central que articulou as perspectivas individuais e institucionais e que, muito provavelmente, seja uma tensão presente em todo o campo educativo. Esta tensão precisa ser entendida como atravessada por um olhar pessimista que gera uma imagem da EJA como um caminho íngreme e um espaço pedagógico de conflitos.

\section{A PERSISTENTE DICOTOMIA ENTRE TEORIA E PRÁTICA}

O indicativo de que a relação teoria e prática se constitui uma preocupação nos cursos de Pedagogia do Rio de Janeiro se manifestou em duas etapas da pesquisa: a primeira manifestação foi quando estávamos fazendo o levantamento das disciplinas e a segunda no processo de entrevistas.

É importante destacar que os programas das disciplinas não estão disponibilizados nos sítios web dos cursos, mas já no primeiro olhar sobre as grades curriculares que localizamos, os nomes das disciplinas começaram a chamar nossa atenção. Embora a maior parte dos cursos conte com apenas uma disciplina, encontramos a tendência de aliar a questão teórica ou dos fundamentos às questões práticas e metodológicas, o que é para nós mais um indício de que os cursos estão preocupados com a relação entre teoria e prática.

A disciplina "Educação de Jovens e Adultos" é ministrada em vinte cursos. Encontramos também cinco cursos que apresentavam uma pequena variação: "Educação de Jovens e Adultos I", quatro deles por terem uma segunda disciplina denominada "Educação de Jovens e Adultos II". 
Buscando aliar a questão teórica ou dos fundamentos às questões práticas e metodológicas, encontramos nove disciplinas que se chamavam: "Fundamentos Teóricos e Metodológicos da Educação de Jovens e Adultos"; "Fundamentos e Práticas na Educação de Jovens e Adultos"; e "Educação de Jovens e Adultos: Teoria e Metodologia”. Outro movimento importante, embora tímido, que detectamos em um dos cursos, é que as disciplinas de Ensino de Língua Portuguesa, de Matemática, de Geografia, de História, de Ciências da Natureza não são voltadas apenas para a infância, mas passam a incorporar os jovens e os adultos. Certamente incorporar as palavras "jovens" e "adultos" ao título de uma disciplina não é garantia de que esses sujeitos sejam de fato incorporados a ela, pois isso vai depender da formação e/ou da disposição do professor responsável. ${ }^{7}$ De qualquer modo, nos parece importante a iniciativa, já que é fundamental a construção de conhecimentos e metodologias específicas para a EJA nas mais variadas áreas do conhecimento.

Também nos chamou a atenção, no caso dos cursos que oferecem duas ou mais disciplinas, que há disciplinas específicas para abordar os aspectos teóricos ou dos fundamentos e, também, para trabalhar aspectos práticos e metodológicos como por exemplo o par "Fundamentos da Educação de Jovens e Adultos" e "Ensino Fundamental - primeiro Segmento e EJA" e o trio "Fundamentos da Educação de Jovens e Adultos", "Metodologia da Educação de Jovens e Adultos - Prática Pedagógica VI" e "Estágio Supervisionado em Educação de Jovens e Adultos”.

Entretanto, encontramos apenas quatro disciplinas de estágio em EJA a saber: ${ }^{9}$ Estágio Supervisionado em Educação de Jovens e Adultos; Estágio em EJA; Pedagogia do Saber Docente e Estágio: Educação de Jovens e Adultos; e Pedagogia nas Instituições e nos Movimentos Sociais: Estágio Supervisionado.

Esse quadro revela que os estágios, nos cursos de Pedagogia, continuam centrados na Educação Infantil e no Ensino Fundamental chamado "regular" e que a modalidade EJA ainda é pouco contemplada. Além disso, revela o que Paiva (2006) identifica como as duas vertentes de EJA que se consolidam nos anos posteriores à V Conferência Internacional de Educação de Jovens e Adultos (V Confintea): a escolarização e a educação continuada. Ao acontecer em escolas e

\footnotetext{
${ }^{7}$ Essa perspectiva foi levantada na entrevista concedida pela professora da IES em questão.

${ }^{8}$ Foram também encontradas, com certa frequência, disciplinas denominadas "Educação e Trabalho" e "Educação Popular e Movimentos Sociais" ou com uma formulação um pouco diferenciada como "Fundamentos da Educação de Jovens e Adultos e Educação Popular". Além disso, foram encontradas disciplinas combinando EJA com outras áreas, como "Pesquisa e Prática Pedagógica na EJA e Educação Especial” e "Estágio Supervisionado em (apoio escolar) e Estágio Supervisionado em Educação de Jovens e Adultos”.

9 As referidas disciplinas são oferecidas em cinco cursos, pois uma das IES tem unidades em dois municípios diferentes.
} 
também em outras instituições e nos movimentos sociais, a realização do estágio passa a significar a possibilidade de os futuros pedagogos terem contato com experiências de EJA que ocorrem na escola e fora dela.

A relevância do estágio ficou também evidenciada nas entrevistas, já que todos os professores entrevistados fizeram menção à sua importância ou às dificuldades enfrentadas para sua realização. Segundo um dos professores entrevistados, o estágio introduzido no curso no qual trabalha há três semestres, foi considerado um avanço, pois:

Ajudou muito a redesenhar a disciplina teórica, trazendo a prática. Antes as alunas não conseguiam perceber na prática aquilo que a gente estava estudando e quando começou o estágio, a prática veio para reforçar aquilo que estava sendo colocado enquanto estudo [...] No estágio elas já trazem novas significações, que são trazidas para debate, conversa, reflexões e escrevem o que pensam, enfim, é um processo dinâmico e dialético.

Outra professora ressaltou uma questão relacionada ao estágio. Não parece ser consenso em seu curso, mas não apenas no seu, se o estágio deve ou não ser supervisionado, ou seja, se um professor da universidade deve ou não acompanhar os alunos à escola. Os professores que defendem a supervisão, o fazem com base na "desconfiança" de que os alunos possam não ir à escola e forjar relatórios. A entrevistada afirma que a relação entre professores e alunos deve se fundar na confiança e que, por isso a concepção de estágio que vigora no curso é a "de que o professor não precisaria ir na classe com os alunos". O estágio se operacionaliza de forma que "os alunos vão e têm um dia na semana que encontram o professor, então eles narram o que vivenciaram e debatem com você".

Gostaríamos de destacar duas situações que nos ajudam a pensar a dicotomia entre teoria e prática na formação de professores de EJA.

A primeira situação está exemplificada no relato de uma das professoras entrevistadas que expressou a dificuldade de trabalhar com a velha perspectiva de "olha, deixe a teoria de vocês lá na faculdade porque a prática aqui é outra coisa. A teoria de vocês não vai servir pra nada." O que a professora indicou, é uma sensação verificada em outras entrevistas, que os professores que atuam em turmas de educação básica de EJA recebem os estagiários dessa maneira, e que ela classificou como "assustadora".

A professora identificou, então, que o problema é que "há um desencontro muito grande entre teoria e prática". Ela afirmou que os alunos "começam a identificar que a escola, a prática pedagógica na escola está cada vez mais desligada da fundamentação teórica”. A professora destaca 
que essa situação precisa ser mais discutida entre os professores do curso de Pedagogia, especialmente em seus processos de reestruturação curricular.

Como já indicamos, esta dicotomização teoria/prática pedagógica é antiga, não ocorre apenas na EJA nem no Brasil. Vamos começar a elaborar essas questões a seguir. Uma outra situação que nos serve para a tensão teoria/prática pedagógica, surgiu numa entrevista quando um professor faz referência à articulação da "disciplina teórica" com o estágio como uma novidade bastante positiva no curso. Ele afirmou:

[...] a gente conseguiu de uma certa forma organizar que as disciplinas que têm especificidades como educação infantil, EJA, educação especial, sejam atreladas ao estágio. Então, são 60 horas de disciplina teórica e 60 horas de estágio que são dadas pelo mesmo professor. Assim eu trabalho com a mesma turma a parte teórica da disciplina propriamente dita e faço acompanhamento de estágio deles. E tem sido super legal...

O professor destacou que organizou a disciplina teórica de modo a tratar das dimensões históricas, legais, pedagógicas da EJA para, no final, “entrar numa perspectiva em prática [...] como eles estão vivenciando o estágio, eles já vêm com algumas experiências, com algumas questões".

Entretanto, como na primeira situação, as perspectivas trazidas pelos alunos sobre as práticas dos professores das turmas de educação básica de EJA não são tão positivas, principalmente à medida que os estudantes vão avançando na disciplina teórica e no estágio. $\mathrm{O}$ professor chega a afirmar que os alunos "ficam muito desesperados [...] e passam a ter uma posição bastante crítica e começam, de certa forma, a questionar as propostas que estão sendo apresentadas, que o professor da educação básica tem trabalhado".

O entrevistado acaba por revelar uma angústia que tem sentido ao realizar esse trabalho:

Por um lado tem sido muito legal, pois os alunos vão podendo analisar a experiência partindo do que a gente está discutindo em sala de aula, mas ao mesmo tempo, eu tenho me sentido um pouco angustiado no sentido de que acaba não avançando, sabe? Então, eu tenho percebido de que são as mesmas experiências, as mesmas práticas que os alunos estão vivenciando. E em algumas escolas acaba sendo muito ruim o que eles estão vivenciando. Então, acaba não contribuindo muito, entendeu?

A solução encontrada pelo professor foi colocar os alunos em contato com professores de EJA de diferentes áreas que atuam na educação básica e que têm "práticas diferenciadas" para organizar oficinas e preparar materiais alternativos. Assim os alunos "acabam tendo a oportunidade de ver algo que não é aquilo que muitas das vezes eles estão vendo em sala de aula de EJA". Além disso, os alunos são instados a preparar uma aula que assistiu no estágio, mas de "uma forma 
completamente diferente", pois fundamentada no que foi discutido na disciplina teórica e nas práticas dos professores convidados.

Nos dois exemplos apresentados fica evidente que a dicotomia teoria/prática cruza todas as dimensões da formação dos estudantes nos cursos da EJA. Muitos professores de educação básica criticam a formação universitária por ser "muito teórica" e "pouco prática" e que teria um olhar muito desqualificador sobre a escola básica. Simultaneamente, muitos professores universitários criticam as "práticas" de EJA nas escolas básicas porque infantilizam os estudantes, por ter uma orientação conteudista que não dialoga com as experiências de vida e de trabalho dos alunos, e a falta de criatividade. Neste fogo cruzado de críticas entre universidade e educação básica, os alunos nos cursos de Pedagogia não têm muitos espaços de reflexão e experimentação sobre como superar a dicotomização teoria/prática pedagógica.

Esta pesquisa confirma que a falta de colaboração entre os cursos de Pedagogia e as escolas de educação básica é uma das barreiras mais complexas para poder gerar espaços e oportunidades de superação à dicotomização teoria/prática pedagógica, o que contribuiria para a melhoria das oportunidades educativas no Brasil.

\section{CONCLUSÕES}

Retomando a pergunta inicial do texto, existem amplas evidências ${ }^{10}$ de que muitos pesquisadores em educação encontram respostas para a questão de como mudar ideias que causam danos, seguindo um modelo tradicional "iluminista" (WEIS, 1977). Idealmente, quando este modelo funciona efetivamente, após considerar as fontes relevantes de dados, os interesses econômicos, as motivações políticas e as preferências ideológicas daqueles que se beneficiam da manutenção do status quo, os pesquisadores geram investigações de alta qualidade, claras e acessíveis, que servirão para corrigir e modificar as ações daqueles que seguem as tradições danosas. Para os seguidores deste modelo, a forma de transformar o modo de as pessoas pensarem é confrontar as ideias que causam danos com dados concretos e argumentos bem sustentados. Tratase de um modelo poderoso que, em muitos casos, funciona relativamente bem, mas que infelizmente não é tão eficaz como gostaríamos. ${ }^{11}$

\footnotetext{
${ }^{10}$ Ver, entre outros, os trabalhos de Berliner, 2002; Biddle, Saha, 2005; Nutley et al., 2007; OECD, 2007; Southerland, Gadsden, Herrington, 2014; Tseng, 2012; Yohalem, Tseng, 2015.

11 A tradição do modelo produtor-indutor "iluminado" é também criticada por ser positivista e elitista e os pesquisadores o defendem por estarem mais preocupados com a função de seleção da informação do que com potenciais contribuições para o bem público (TSENG, 2012).
} 
Um dos principais problemas do modelo iluminista é que a mudança das perspectivas das pessoas a respeito de noções profundamente arraigadas não pode ser feita sem se considerar o "preconceito confirmatório" (KAHNEMAN, 2011), e "entender que uma afirmação deve começar com a tentativa de se acreditar nela: você deve primeiro saber o que a ideia significaria se ela fosse verdadeira. Somente então poderá decidir se desacredita nela ou não (KAHNEMAN 2011, p. 81, grifos do autor no original). ${ }^{12}$

Outra limitação muito importante do modelo iluminista é que certas tradições, mesmo aquelas que visivelmente causam danos, podem permanecer fortes devido ao poder das ideias zumbi corretamente erradas. Em todas as suas partes descoordenadas, na sua feiura, erro e injustiça, se recusam a desaparecer e, em muitos casos, aparecem como gravadas em pedras, e, portanto, impossíveis de serem mudadas. Esforços para alterar ou erradicar uma ideia zumbi corretamente errada são em geral rotulados de quixotescos ${ }^{13}$ porque, para serem desmontados, precisam não apenas da cooperação e do entendimento das pessoas que viveram ou testemunharam a dor e o sofrimento causados por aquelas tradições, mas também da concordância daqueles que se beneficiam delas. Precisamos ainda trabalhar muito para impedir a divulgação e a reprodução de ideias corretamente erradas sobre a EJA.

Nesse trabalho, tentamos ir além do modelo "iluminista", identificando e denunciando ideias zumbi, tais como a persistência da burrice e a dicotomia teoria/prática que constituem desafios relevantes na EJA, tomando cuidado para não cair na tentação de oferecer o tradicional "é preciso mais pesquisas" sem tomar em conta a grande quantidade de investigações robustas já produzidas. Por essa razão, queremos insistir na importância e na responsabilidade dos pesquisadores do campo da EJA em trabalhar para desarticular as ideias zumbi que seguem invadindo a formação profissional.

A escassa produtividade de estruturar a formação docente para a EJA baseada numa separação entre a teoria e a prática pedagógica foi contestada há muito tempo (FREIRE, 1987; CARR, KEMMIS, 1986), já que toda prática possui uma teoria que a fundamenta, implícita ou explicitamente, da mesma maneira que as teorias pedagógicas têm implícitas práticas pedagógicas

\footnotetext{
${ }^{12}$ Segundo Arbesman (2012) e Churchland (2013), ignorar evidências sólidas que confirmam nossos modelos mentais é muito comum e é conhecido na literatura como o Reflexo de Semmelweis. Em meados dos anos 1800, o médico húngaro Ignaz Semmelweis provou que quando os médicos desinfetavam as mãos antes da cirurgia, as fatalidades de pacientes eram reduzidas por prevenir infecções. Infelizmente, o grupo médico de plantão do dia rejeitou a pesquisa de Semmelweis considerando-a sem fundamento e, até mesmo, um insulto à dignidade dos médicos. Somente muitos anos depois, a lavagem de mãos defendida por Semmelweis se tornou uma prática obrigatória para salvar vidas.

${ }^{13}$ Com frequência, aqueles que se beneficiam do status quo rotulam os esforços para mudanças de Quixotesco.
} 
possíveis. A nossa perspectiva é que uma forma mais produtiva de avançar sobre a mútua desconfiança entre cursos de Pedagogia e escolas de educação básica precisa reconhecer que as críticas mútuas podem ser corretas ou corretamente erradas, mas elas se conectam com as percepções dos sujeitos envolvidos e, portanto, ficar na crítica sem tomar em conta a importância dos "preconceitos confirmatórios", ou alterar os incentivos que regulam os modelos de relacionamento entre pesquisadores, formadores e docentes da educação básica é a receita segura para não resolver os problemas nem dos cursos de formação nem das escolas (FISCHMAN, 2016).

Sabemos que uma mudança nos modelos de relacionamento entre os cursos de Pedagogia e as escolas não é uma tarefa simples, embora já se tenha bastante evidência sobre o potencial transformador de estabelecer relações de colaboração e intercâmbio entre os cursos de Pedagogia e a escolas de ensino básico, abandonando a clássica divisão do trabalho pedagógico que atribui à universidade a formação teórica e às escolas o espaço da "prática" (GATTI, 2010; NÓVOA, 2007; SHULMAN, 2005). As reflexões de Nóvoa (2007, p. 24) são apropriadas:

Pela minha parte, advogo um sistema semelhante para a formação de professores: estudo aprofundado de cada caso, sobretudo dos casos de insucesso escolar; análise colectiva das práticas pedagógicas; obstinação e persistência profissional para responder as necessidades e anseios dos alunos; compromisso social e vontade de mudança. Na verdade, não é possível escrever textos atrás de textos sobre a práxis e o practicum, sobre a phronesis e a prudentia como referências do saber docente, sobre os professores reflexivos, se não concretizarmos uma maior presença da profissão na formação. É importante assegurar que a riqueza, a complexidade e a beleza do ensino "saiam do armário", como pretende Lee Shulman, adquirindo a mesma visibilidade de outros campos de trabalho académico e criativo. E, ao mesmo tempo, é essencial reforçar dispositivos e práticas de formação de professores baseados na investigação.

As parcerias entre escolas e universidades no modelo de residência (NÓVOA, 2007) enfatizando a usabilidade da pesquisa pedagógica (FISCHMAN, 2016) e a relevância de espaços de experimentação pedagógica oferecem alternativas que seriam importantes e possíveis de implementar na EJA. Nossas recomendações não podem ser implementadas como um toque de mágica sem abordarmos a política principal e os desafios culturais que geram as tensões identificadas: a possibilidade de aumentar o número e a qualidade de educadores de EJA demanda simultaneamente outras perspectivas sobre a formação, assim como recursos financeiros adicionais, já previstos no Fundeb, mas também profundas mudanças institucionais, sociais e culturais. Contudo, estes recursos e mudanças não podem ser promovidos sem se desmontar os legados de políticas de ajuste estruturais e o poderoso controle das agendas econômicas neoliberais que, sem 
dúvida, se ainda restringem, não eliminam o potencial e a esperança de ações voltadas para a justiça social, política e pedagógica.

Para nós está absolutamente claro que investigar este problema sem perder a esperança14 requer uma crítica aos regimes neoliberais, sem ignorar as questões básicas da educação, para quem e para quê, e reconhecer que as escolas e organizações educacionais são locais de luta e de relações de poder que emergem em diferentes ambientes culturais e políticos. Precisamos ser mais inteligentes e aceitar o desafio do grande escritor italiano Italo Calvino (1988, p. 7) que exorta a todos nós sobre o que fazer quando os problemas são difíceis:

Sempre que a humanidade parece estar condenada à opressão, acho que devo voar como Perseu para um espaço diferente. Não quero dizer escapar nos sonhos ou no irracional. Eu quero dizer que tenho que mudar a minha abordagem, olhar para o mundo a partir de uma perspectiva diferente, com uma lógica diferente e com novos métodos de cognição e verificação.

\section{REFERÊNCIAS}

ARBESMAN, S. The half-life of facts: Why everything we know has an expiration date. New York, NY: Penguin, 2012.

BERLINER, D. C. Educational research: The hardest science of all. Educational Researcher, 31 (8), p. 18-20, 2002.

BRASIL. Constituição (1988). Constituição da República Federativa do Brasil. Diário Oficial da União. Brasília: Congresso Nacional, 05 out. 1988. Anexo.

. Lei 9.394, de 20 de dezembro de 1996. Estabelece as diretrizes e bases da educação nacional. Diário Oficial da União. Brasília: Poder Legislativo, 23 dez. 1996, sec. I, n. 248, p. 27.833.

Lei 9.424. Dispõe sobre o Fundo de Manutenção e Desenvolvimento do Ensino Fundamental e de Valorização do Magistério - Fundef. Diário Oficial da União. Brasília: Poder Legislativo, 26 dez. 1996, sec. I, p. 28.442 .

Lei 11.494. Regulamenta o Fundo de Manutenção e Desenvolvimento da Educação Básica e de Valorização dos Profissionais da Educação - Fundeb. Diário Oficial da União. Brasília: Poder Legislativo, 20 jun. 2007 , sec. I, p. 7.

; MEC. Documento Base Nacional Preparatório à VI Confintea. Brasília, 2008.

BIDDLE, B. J., SAHA, L. J. The untested accusation: principals, research knowledge, and policy making in schools. Westport, CN: Ablex, 2002.

CALVINO, I. Six Memos for the Next Millennium. Cambridge, Massachusetts: Harvard University Press, 1988.

CARR,W.; KEMMIS, S. Teoría crítica de la enseñanza. La investigación-acción en la formación del profesorado. Barcelona: Martínez Roca, 1986.

CHURCHLAND, P. Touching a nerve: the self as brain. New York, NY: W. W. Norton, 2013.

DI PIERRO, M. C. Notas sobre a redefinição da identidade e das políticas de EJA no Brasil. Educação e Sociedade, Campinas, vol. 26, n. 92, p. 1115-1139, Especial - Out. 2005.

FÁVERO, O. Políticas públicas de educação de jovens e adultos no Brasil. In: SOUZA, J. S.; SALES, S. R. Educação de Jovens e Adultos: Políticas e práticas educativas. Rio de Janeiro: Nau Editora, EDUR, 2011. p. 29-47.

\footnotetext{
${ }^{14}$ Embora os autores do livro não detalhem sobre a noção de esperança, estamos convencidos que eles concordam com Rorty (1999, p. xxiii), que se refere à esperança social como a capacidade humana mais marcante e prazerosa, "nossa habilidade de confiar e cooperar com outras pessoas e, em particular, trabalhar juntos para melhorar o futuro".
} 
FISCHMAN, G. E. Education research: for whom and to what end? An analysis of knowledge mobilization strategies developed by Schools of Education final report submitted to the Spencer Foundation, 2016. (mimeo).

; SALES, S. R. O que é a educação de jovens e adultos para os de dentro e os de fora? Uma análise dos protótipos de "educação", “jovens" e "adultos” nas revistas Veja e Isto É. In: ANPED. Anais... da 35" Reunião Anual. Porto de Galinhas, 2012.

FREIRE, P. Pedagogia do Oprimido. São Paulo: Paz e Terra, 1987.

GALVÃO, A. M. O.: DI PIERRO, M. C. Preconceito contra o analfabeto. São Paulo: Cortez, 2007.

GATTI, B. Formação de professores no Brasil: características e problemas. Educação \& Sociedade, Campinas, v. 31, n. 113, p. 1355-1379, out.-dez. 2010. Disp.: <http://www.cedes.unicamp.br>. Acesso: 10 abr. 2016.

HADDAD, S. A educação de pessoas adultas e a nova LDB. In: BRZEZINSKI, I. (Org.). LDB interpretada: diversos olhares de entrecruzam. São Paulo: Cortez, 1998. p. 111-127.

HAIDT, J. The righteous mind: why good people are divided by politics and religion. New York, NY: Pantheon, 2013.

HASS, E. M.; FISCHMAN, Gustavo E.; BREWER, J. Dumb Ideas Won't Create Smart Kids: Straight Talk About Bad School Reform, Good Teaching, and Better Learning. New York: Teachers College Press, 2014.

HELLER, N. High Score. A new movement seeks to turn life's challenges into a game. Disp.: <http://www.newyorker.com/magazine/2015/09/14/high-score>. Acesso: jun. 2015.

KAHNEMAN, D. Thinking, fast and slow. New York, NY: Farrar, Straus and Giroux, 2011.

KRUGMAN, P. Jobs and skills and zombies. New York Times. Disponível em http://www.nytimes.com/2014/03/31/opinion/krugman-jobs-and-skills-and-zombies.html?_r=0. Acesso em 30 mar. 2014.

MACHADO, M. M. Diálogos necessários sobre a gestão e o financiamento da EJA. In: SOUZA, J. dos S.; SALES, S. R. Educação de Jovens e Adultos: Políticas e práticas educativas. Rio de Janeiro: Nau Editora, EDUR, 2011, p. 87109.

NÓVOA, António. O regresso dos professores. p. 21-28. In: Unidos aprendemos: reforçar a cooperação para a equidade e para a qualidade da aprendizagem ao longo da vida. Lisboa: Ministério da Educação, Direcção-Geral dos Recursos Humanos da Educação, 2007.

NUTLEY, S., WALTER, I., DAVIES, H. Using evidence: how research can inform public services. Bristol: Policy Press, 2007.

OCDE. Evidence in Education. Linking Research and Practice. Paris: OECD, 2007.

Paiva, J. Tramando concepções e sentidos para redizer o direito à educação de jovens e adultos. Revista Brasileira de Educação, v. 11, n. 33, set./dez, 2006.

RORTY, R. Philosophy and Social Hope. London: Penguin Books, 1999.

RUMMERT, S. M., VENTURA, J. P. Políticas públicas para educação de jovens e adultos no Brasil: a permanente (re)construção da subalternidade - considerações sobre os Programas Brasil Alfabetizado e Fazendo Escola. Educar, Curitiba, n. 29, p. 29-45, 2007.

SALES, S. R., PAIVA, J. As muitas invenções da EJA. Archivos Analíticos de Políticas Educativas / Education Policy Analysis Archives., v.1, p.1 - 17, 2014.

SHULMAN, L. Excellence: An immodest proposal. STANFORD, CA. The Carnegie Foundation for the Advancement of Teaching, 2005.

SOUTHERLAND, S. A., GADSDEN, V. L., HERRINGTON, C. D. Editors' introduction: What should count as quality education research? Continuing the discussion. Educational Researcher, 43 (7), p. 6-8, 2014.

TSENG, V. The uses of research in policy and practice. Social policy report, 26 (2). Disponível em http://www.wtgrantfoundation.org/publications_and_reports/browse_reports/v-tseng-social-policy-report-2012. Acesso em ago. 2012.

WEISS, C. H. Research for policy's sake: the enlightenment function of social research. Policy Analysis, 3 (4), p. 531$545,1977$.

YOHALEM, N., TSENG, V. Commentary: Moving From Practice to Research, and Back, Applied Developmental Science, 19:2, p. 117-120, 2015. 


\section{RESUMO}

Nesse trabalho, apresentamos os resultados de uma pesquisa sobre a Educação de Jovens e Adultos (EJA) nos Cursos de Pedagogia do estado do Rio de Janeiro, a partir de uma revisão de uma revisão das grades curriculares dos cursos e de entrevistas em profundidade com professores que ministram disciplinas de EJA em IES públicas e privadas. $\mathrm{Na}$ análise dos dados, a relação entre teoria e prática pedagógica na EJA foi a tensão central que articulou as perspectivas individuais e institucionais. Esta tensão apareceu atravessada por um olhar pessimista que gera uma imagem da EJA como um caminho íngreme e um espaço pedagógico de conflitos. Neste texto discutimos que algumas dessas caracterizações estão articuladas a partir de ideias zumbi, que são aquelas que "deveriam ter sido mortas pela evidências, mas se recusam a morrer." Nas conclusões propormos a necessidade de desenvolver novos modelos de relacionamento entre os cursos de Pedagogia e as escolas, estabelecendo relações de colaboração e intercâmbio entre os cursos de Pedagogia e as escolas de educação básica abandonando a divisão de tarefas que atribui à universidade a "teoria" e às escolas as "práticas".

Palavras-chave: Educação de Jovens e Adultos; Cursos de Pedagogia; dicotomia Teoria/Prática; ideias zumbi.

\section{PROPOSALS TO GO BEYOND THE "PERSISTENCE OF DUMBNESS" AND OTHER "ZUMIBI IDEAS" IN EJA}

\section{ABSTRACT}

In this work we present the results of a survey of Youth and Adult education Teacher Training Programs in Rio de Janeiro. We analyzed the pedagogical projects, the curricula of the courses and conducted in-depth interviews with teachers who teach EJA in public and private universities. In the data analysis, the relationship between theory and practice in adult education was the central tension that articulated the individual and institutional perspectives. This tension is framed by a pessimistic look that generates an image of the EJA as a steep path and a conflictive pedagogical space. In this paper we discuss that these characterizations are articulated by zombie ideas, those that "should have been killed by the evidence, but refuse to die." In the conclusions we argue for developing new models of relationships between teacher education programs and basic schools, establishing collaborative relationships and exchanges between teaching courses and basic schools abandoning the division of tasks that assign to the university 'theoretical work' and see schools just "practical spaces."

Keywords: Youth and Adult education; teacher education programs; dichotomy theory/practice; zombie ideas. 